\title{
A Systematic Review of Side Effects of Nucleoside and Nucleotide Drugs Used for Treatment of Chronic Hepatitis B
}

\author{
Vandana Khungar • Steven-Huy Han
}

Published online: 21 April 2010

(C) The Author(s) 2010. This article is published with open access at Springerlink.com

\begin{abstract}
Although nucleosides and nucleotides have a good safety record for the treatment of hepatitis B, there have been no systematic reviews on this topic. We searched Medline to include studies of the oral antiviral agents for hepatitis B and adverse events, with at least 48 weeks of follow-up from the initiation of treatment with the drug. Important toxicities include nephrotoxicity, myopathy, and resistance. It is often difficult to ascertain whether an adverse effect is from the study drug or the natural progression of the disease. Further safety data are needed for the newer agents and for all agents with regard to patients with decompensated liver disease, renal dysfunction, the elderly, children, and pregnant women.
\end{abstract}

Keywords Nucleosides · Nucleotides $\cdot$ Chronic hepatitis B virus infection · Lamivudine · Entecavir · Telbivudine .

Adefovir dipivoxil $\cdot$ Tenofovir disoproxil fumarate

\section{Introduction}

Worldwide, 350 to 400 million people have chronic hepatitis B virus infection (CHB). Among those chronically

\author{
V. Khungar $\cdot$ S-H. Han \\ Division of Digestive Diseases, \\ David Geffen School of Medicine \\ at University of California, Los Angeles, \\ Los Angeles, CA, USA \\ V. Khungar \\ e-mail: VKhungar@mednet.ucla.edu \\ S-H. Han $(\square)$ \\ Pfleger Liver Institute, David Geffen School of Medicine at \\ University of California, Los Angeles, \\ 200 UCLA Medical Plaza, Suite 214, \\ Los Angeles, CA 90095, USA \\ e-mail: steven.han@ucla.edu
}

infected, $20 \%$ to $40 \%$ develop cirrhosis, decompensated liver disease, or hepatocellular carcinoma. Treatment of CHB has evolved rapidly over the past decade as a result of improvements in antiviral treatment. Initially, interferon- $\alpha$ was the only available treatment, but it is effective in only $35 \%$ of patients and is poorly tolerated because of its adverse effects. The nucleoside/nucleotide medications are an important class of drugs that are changing the way CHB is treated [1]. The aim of this article is to systematically review the literature on side effects of currently approved nucleoside and nucleotide drugs in the treatment of chronic hepatitis B virus (HBV) infection in adults, focusing on adverse events, serious adverse events, resistance, and death. There are currently three nucleoside drugs (lamivudine, entecavir, and telbivudine) and two nucleotides (adefovir dipivoxil, tenofovir disoproxil fumarate) approved in the United States for the treatment of chronic HBV. Prolonged treatment with these oral agents is recommended for selected patients with HBV infection until disease remission or serologic endpoints have been achieved. Indefinite treatment is indicated for patients with HBV and advanced liver disease or in some patients on chronic immunosuppressive therapy $[1,2 \cdot \bullet, 3 \cdot \bullet]$.

The side effect profile for the five approved agents was generally good during registration trials, but there have been reports of serious adverse events including myopathy, neuropathy, pancreatitis and renal impairment during post marketing surveillance. As the oral agents have often been administered to patients with HIV coinfection, it is sometimes difficult to ascertain the role of HIV on reported adverse events $[1,2 \bullet \bullet]$. This important population cannot be ignored, however. Every effort will be made in this article to review the side-effects of these drugs in patients with hepatitis B or for hepatitis B/HIV coinfection, and articles reporting adverse events exclusively in patients with HIV 
monoinfection will be excluded. Though there have been important narrative reviews on adverse side-effects with nucleos $(\mathrm{t})$ ide drugs written previously, this article is the first systematic review on the topic to our knowledge.

\section{Established Side Effects of Nucleoside Analogues}

Information on several established side effects of the approved nucleoside and nucleotide drugs used for the treatment of CHB are described in Table 1. Information summarized in Table 1 includes year of approval, abbreviation, mechanism, clearance, dose, renal and dialysisadjusted dose, common side effects, and pregnancy category $[4 \cdot \bullet]$.

The five approved oral agents for CHB are analogues of nucleosides or nucleotides that pharmacologically inhibit the HBV polymerase in order to decrease viral replication and serum HBV DNA levels. Some analogues have activity against human mitochondrial DNA (mtDNA) polymerase gamma and can lead to mitochondrial dysfunction. Mitochondrial toxicity can manifest clinically as one or more of the following: myopathy, neuropathy, hepatic steatosis, pancreatitis, macrocytosis, hyperlactemia, lactic acidosis, and nephrotoxicity. All five approved agents carry a US Food and Drug Administration black box warning of potential mitochondrial toxicity $[4 \bullet \bullet, 5]$. Fialuridine is a nucleoside analogue which caused lactic acidosis, hepatic steatosis, pancreatitis, neuropathy, myopathy, and irreversible liver failure. It irreversibly incorporated into human mitochondrial DNA, causing mitochondrial failure, and was withdrawn from the market as a result [6].

Another important consideration is lactic acidosis, for which all five approved oral agents carry a black box warning. This black box warning originally derived from the HIV literature, though cases have been reported with nucleos $(\mathrm{t})$ ide agents given at the lower doses recommended for CHB. Recently, entecavir was found to cause lactic acidosis in 5 of 16 patients $(31 \%)$ in one study. All of the patients who developed lactic acidosis had highly impaired liver function, with a model for end-stage liver disease (MELD) score $\geq 20$. Lactic acidosis occurred between 4 and 240 days after treatment initiation and was lethal in one patient, but resolved in the others with discontinuation of entecavir. In patients with a MELD score less than 18, no increased serum lactate concentrations were observed. These data indicate that entecavir should be used with caution in patients with impaired liver function [7]. All five medications also carry a black box warning for posttreatment flares of hepatitis. Adefovir dipivoxil carries a warning for potential HIV resistance in HBV treated patients with previously undiagnosed HIV [8-12].

\section{Methods}

We searched Medline for published articles up to October 2009 using a combination of search strings. The first component of the search string was the antiviral drug. For this, we searched each variation of the drug's name, including its trade names as text words, the name of the drug searched as a MeSH term, and the substance name of the drug. These variations were strung together with the "OR" function in Medline. For example, with lamivudine, the drug search was as follows: ("Lamivudine"[Text Word] OR "3TC"[Text Word] OR "Epivir"[Text Word] OR "Zeffix"[Text Word] OR "Heptovir"[Text Word] OR "Epivir-HBV"[Text Word] OR "Lamivudine"[Mesh] OR "lamivudine triphosphate "[Substance Name]). The second component of our search string was the drug side effects. For this component, we used the following string: ("complicat*"[Text Word] OR "adverse effect*"[Text Word] OR

Table 1 FDA-approved oral antivirals for CHB

\begin{tabular}{|c|c|c|c|c|c|}
\hline & Lamivudine & Adefovir & Entecavir & Telbivudine & Tenofovir \\
\hline Year of approval & 1998 & 2002 & 2005 & 2006 & 2008 \\
\hline Abbreviation & LAM & $\mathrm{ADV}$ & ETV & TBV & TNV \\
\hline $\begin{array}{l}\text { Mechanism of } \\
\text { action }\end{array}$ & $\begin{array}{l}\text { Blocks HBV } \\
\text { reverse transcriptase }\end{array}$ & $\begin{array}{l}\text { Blocks HBV reverse } \\
\text { transcriptase }\end{array}$ & $\begin{array}{l}\text { Inhibits HBV DNA } \\
\text { polymerase }\end{array}$ & $\begin{array}{l}\text { Inhibits HBV } \\
\text { DNA polymerase }\end{array}$ & $\begin{array}{l}\text { Inhibits HBV } \\
\text { DNA polymerase }\end{array}$ \\
\hline Clearance & Renal & Renal & Renal & Renal & Renal \\
\hline Dose & $100 \mathrm{mg} / \mathrm{d}$ & $10 \mathrm{mg} / \mathrm{d}$ & $0.5 \mathrm{mg} / \mathrm{d}$ & $600 \mathrm{mg} / \mathrm{d}$ & $300 \mathrm{mg} / \mathrm{d}$ \\
\hline $\begin{array}{l}\text { Renal and dialysis- } \\
\text { adjusted dose }\end{array}$ & $50 \mathrm{mg} / \mathrm{d}$ & $10 \mathrm{mg} / \mathrm{d}$ & $\begin{array}{l}0.25 \mathrm{mg} / \mathrm{d} \text { or } 0.50 \mathrm{mg} \\
\text { every other day }\end{array}$ & $\begin{array}{l}600 \mathrm{mg} \text { every } \\
\text { other day }\end{array}$ & $\begin{array}{l}300 \mathrm{mg} \text { every } \\
\text { other day }\end{array}$ \\
\hline $\begin{array}{l}\text { Common side } \\
\text { effects }\end{array}$ & $\begin{array}{l}\text { Occasional myopathy, } \\
\text { neuropathy, pancreatitis }\end{array}$ & $\begin{array}{l}\text { Nephrotoxicity, } \\
\text { pancreatitis }\end{array}$ & Negligible & Myopathy & Nephrotoxicity \\
\hline Pregnancy category & $\mathrm{C}$ & $\mathrm{C}$ & $\mathrm{C}$ & $\mathrm{B}$ & $\mathrm{B}$ \\
\hline
\end{tabular}

$C H B$ chronic hepatitis B virus infection, $F D A$ US Food and Drug Administration, $H B V$ hepatitis B virus 
"adverse event*"[Text Word] OR "safe*"[Text Word] OR "drug monitor*"[Text Word] OR "toxic*"[Text Word] OR "poison*"[Text Word] OR etiol*[text word] OR aeitol* [text word] OR causation[text word] OR causal*[text word] OR "complications "[Subheading] OR "adverse effects "[Subheading] OR "Safety"[Mesh] OR "Biomarkers, Pharmacological"[Mesh] OR "Drug Toxicity"[Mesh] OR "Causality"[Mesh] OR "etiology "[Subheading] OR "prevention and control "[Subheading] OR "chemically induced "[Subheading]). The final component of our search string was hepatitis B. We searched the following: ("Hepatitis B"[Mesh] OR "Hepatitis B virus"[Mesh] OR "hepatitis $B "[$ Text Word]). Included under the broader category of "Hepatitis B" in Medline is "Chronic Hepatitis B," obviating the need to explode the MeSH term. Because MeSH subject headings are hierarchical, in order to retrieve a term and its narrower terms, a subject heading must be exploded. PubMed automatically explodes MeSH subject headings to include all narrower terms unless "Do not explode" is selected. Finally, the three components (drug, side effect, and hepatitis B) were combined using the AND function of Ovid Medline. We constructed a publication type hedge in Medline to include the following types of studies: randomized controlled trials, controlled clinical trials, cohort studies, and case-control studies. We did not restrict this review to randomized controlled trials due to lack of randomized controlled trials devoted to reporting harm. We chose our search strategy based on the Cochrane Handbook's Highly Sensitive Search Strategy for identifying randomized trials in MEDLINE: sensitivity and precision maximizing version with the addition of cohort studies and case-control studies.

In the final review, we included all English-language articles if they were 1) original research articles; 2) reported side effects or adverse events of one of the nucleoside or nucleotide drugs; 3 ) reported results for a population with CHB (either with or without HIV); 4) involved only human subjects; and 5) had at least 48 weeks of follow-up. If a phase 3 trial was available, we included the phase 1 or 2 trial only if they contained data not reported in the phase 3 trial. If a trial was reported in two journals, we chose one of the articles.

\section{Results}

\section{Description of Study Characteristics}

Table 2 provides the descriptive characteristics in terms of author, country, study design, number of patients, participant characteristics, length of follow-up, outcomes assessed, and primary purpose of the study for each article included.
Lamivudine

Lamivudine (LAM) was the first oral nucleoside analogue approved for the treatment of CHB, at a dose of $100 \mathrm{mg}$ daily. It is the negative enantiomer of $2^{\prime}-3^{\prime}$ dideoxy-3'thiacytidine. Incorporation of 3TC-TP into growing DNA results in premature chain termination inhibiting HBV DNA synthesis. Lamivudine has been studied extensively and has the well-documented adverse event of liver disease flares due to the emergence of lamivudine-resistant HBV. For the purpose of this review, lamivudine will be discussed in narrative form as hundreds of studies fit the inclusion criteria for this review. Lamivudine was approved for the treatment of CHB in 1998 for adults and in 2001 for children. It was thought to have a side effect profile similar to placebo in registration trials [13]. With prolonged use in postmarketing surveillance, it was noted that genotypic resistance can be detected in $14 \%$ to $32 \%$ after 1 year of lamivudine treatment and up to $70 \%$ after 5 years of treatment $[2 \cdot \bullet]$. Virologic breakthrough in those with LAMresistant virus was usually followed by biochemical breakthrough, with increase in serum alanine transaminase (ALT), followed by acute exacerbations of liver disease and even hepatic decompensation and death. Mutations in the tyrosine-methionine-aspartate-aspartate (YMDD) motif occur frequently and confer genotypic resistance to LAM. Lamivudine is now considered second-line therapy for treatment naïve patients due to this resistance pattern. Rare cases of neuropathy, pancreatitis, Fanconi syndrome, and reversible myopathy have been reported in patients coinfected with HBV and HIV [13].

\section{Adefovir}

Adefovir dipivoxil is the orally bioavailable pro-drug of adefovir (ADV), a nucleotide analogue that inhibits reverse transcriptase and DNA polymerase and causes HBV chain termination. ADV was developed as an antiretroviral for HIV infection but due to nephrotoxicity at high doses, it was not developed for this indication. For CHB, it was approved at a dose of $10 \mathrm{mg}$ daily in 2002. It was approved for children 12 to 17 years of age in 2008. The two most common side effects observed with adefovir therapy are dose-dependent but reversible nephrotoxicity and antiviral resistance $[2 \bullet \bullet$.

Grade 1 nephrotoxicity, defined as serum creatinine $\geq 0.5 \mathrm{mg} / \mathrm{dL}$ above baseline values, was not observed to be an issue in the registration trials for ADV. Postmarketing surveillance revealed a different picture, with $7 \%$ of patients in a cohort of 29 patients coinfected with HIV and LAM-resistant HBV demonstrating grade 1 nephrotoxicity [14]. In a cohort of 185 patients with chronic hepatitis $\mathrm{B}$ e antigen ( $\mathrm{HBeAg}$ )-negative hepatitis $\mathrm{B}$ treated with 


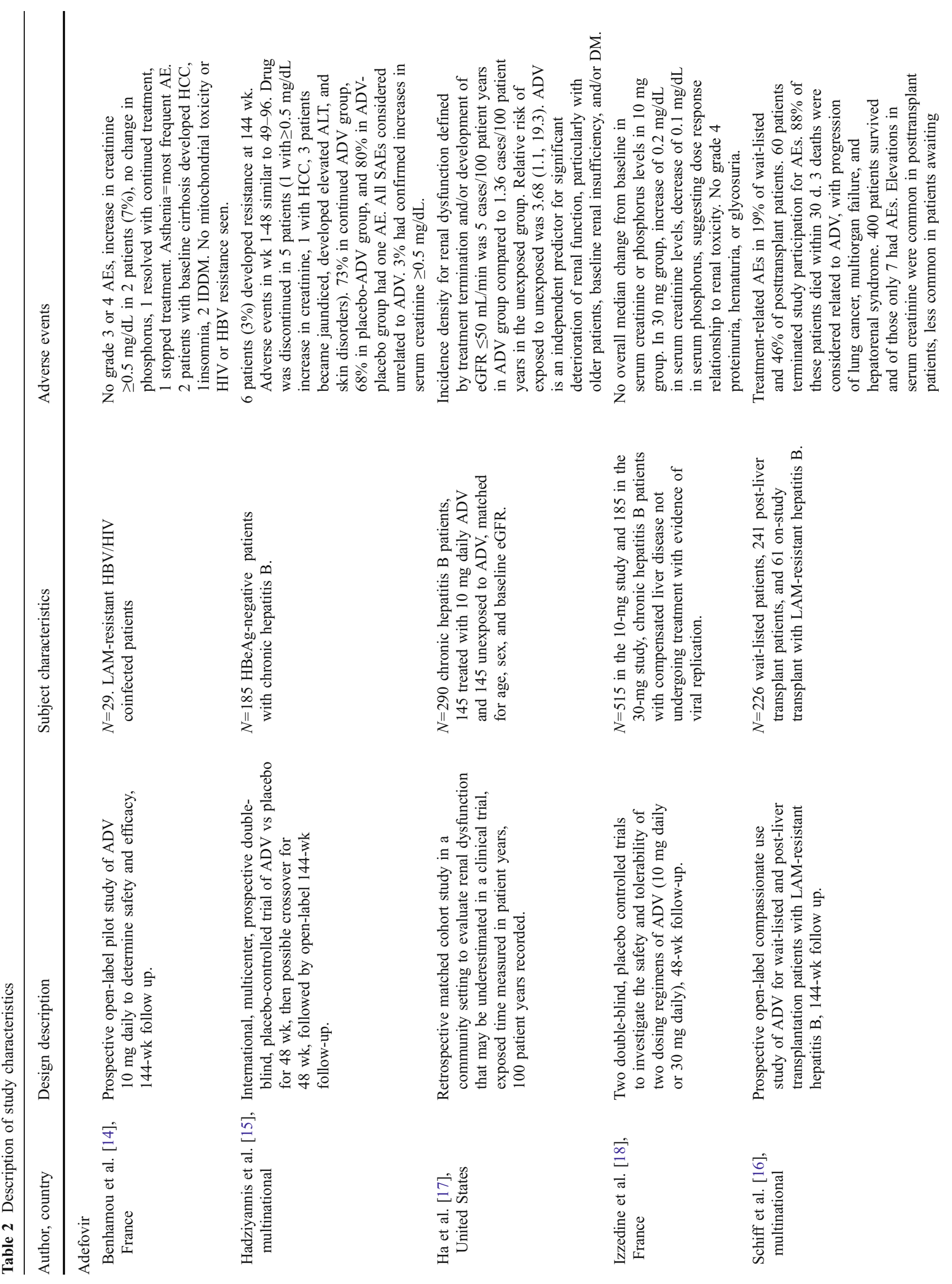



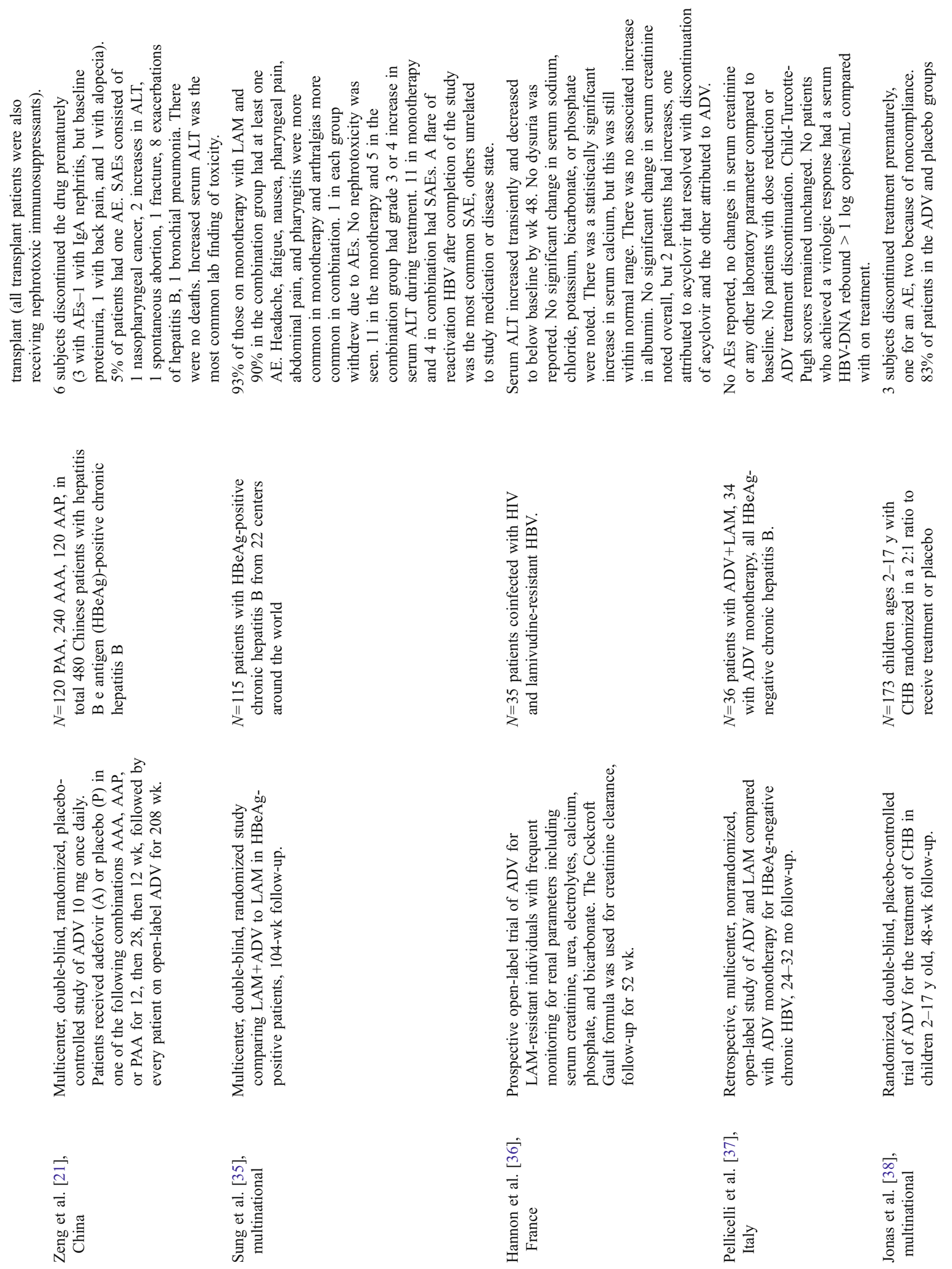


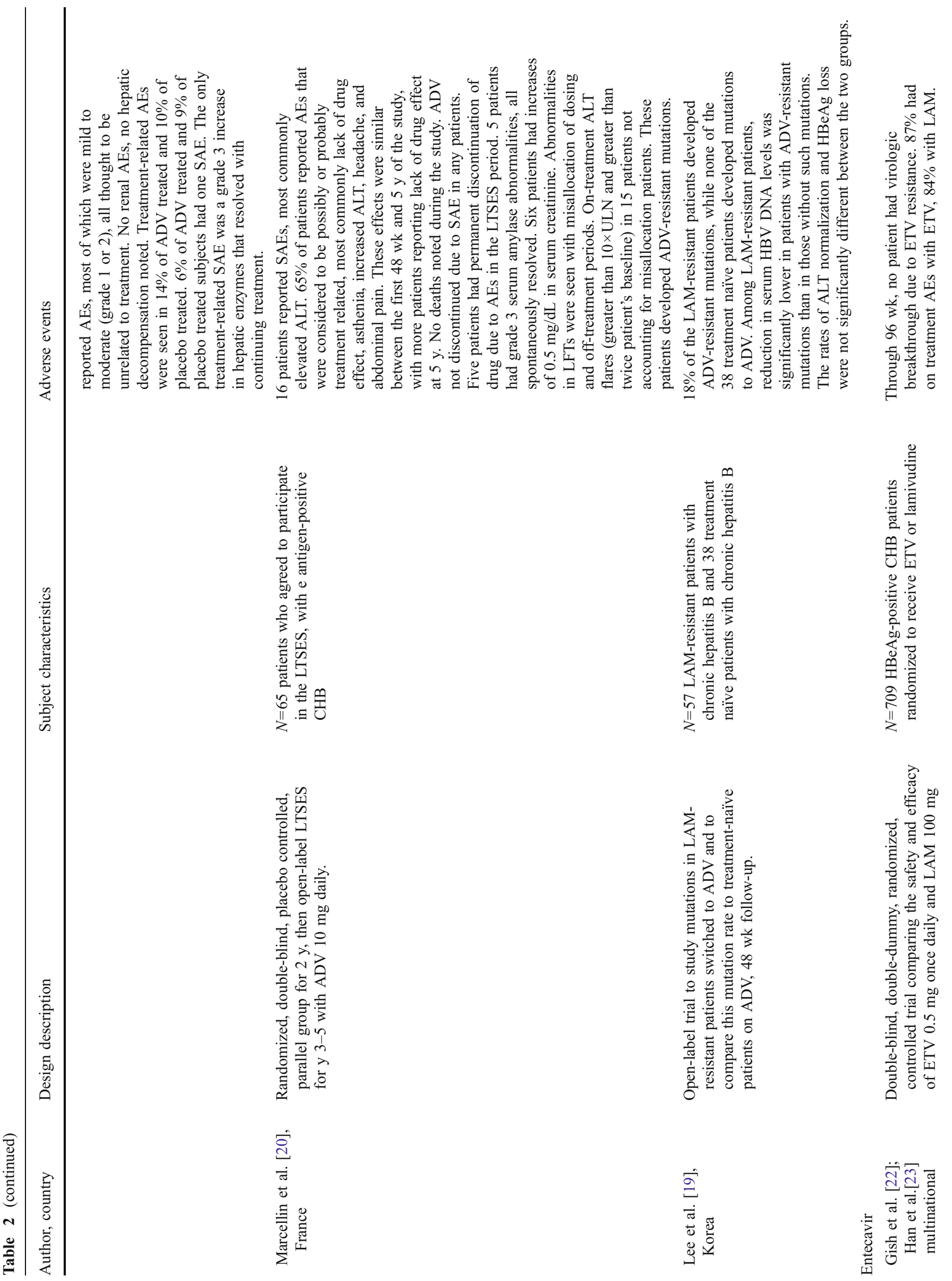




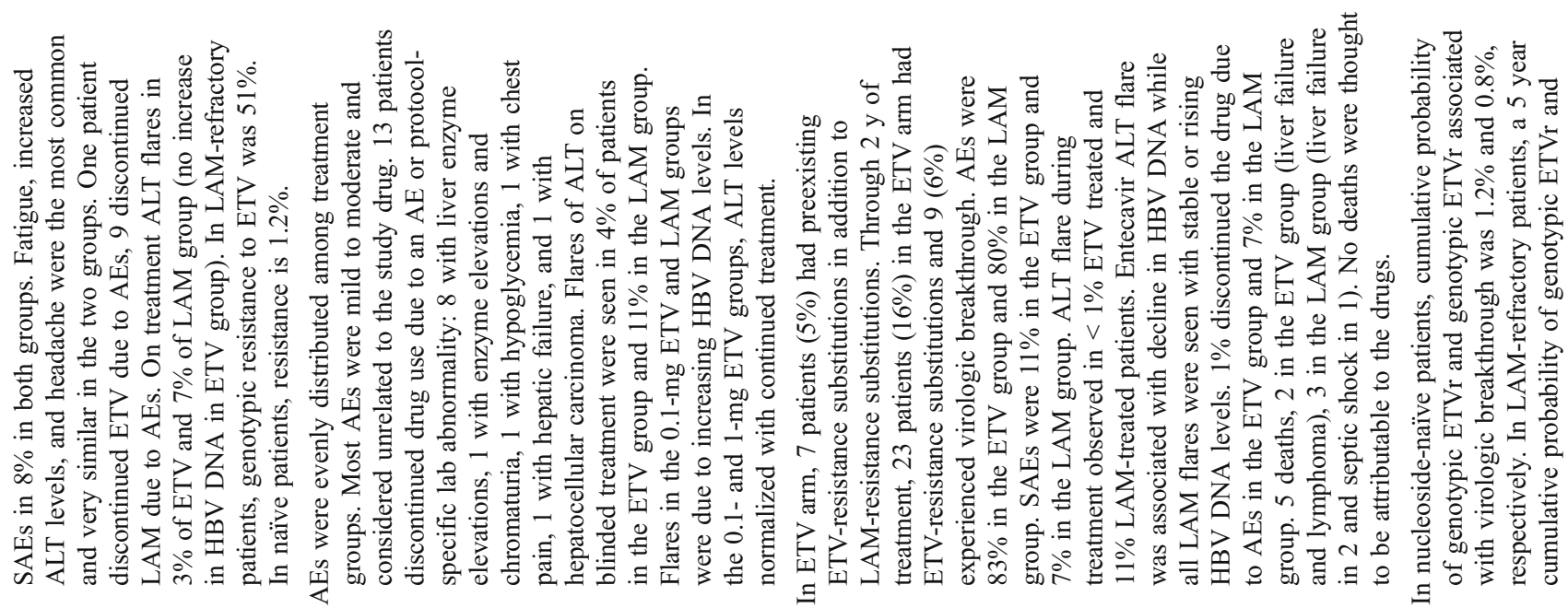

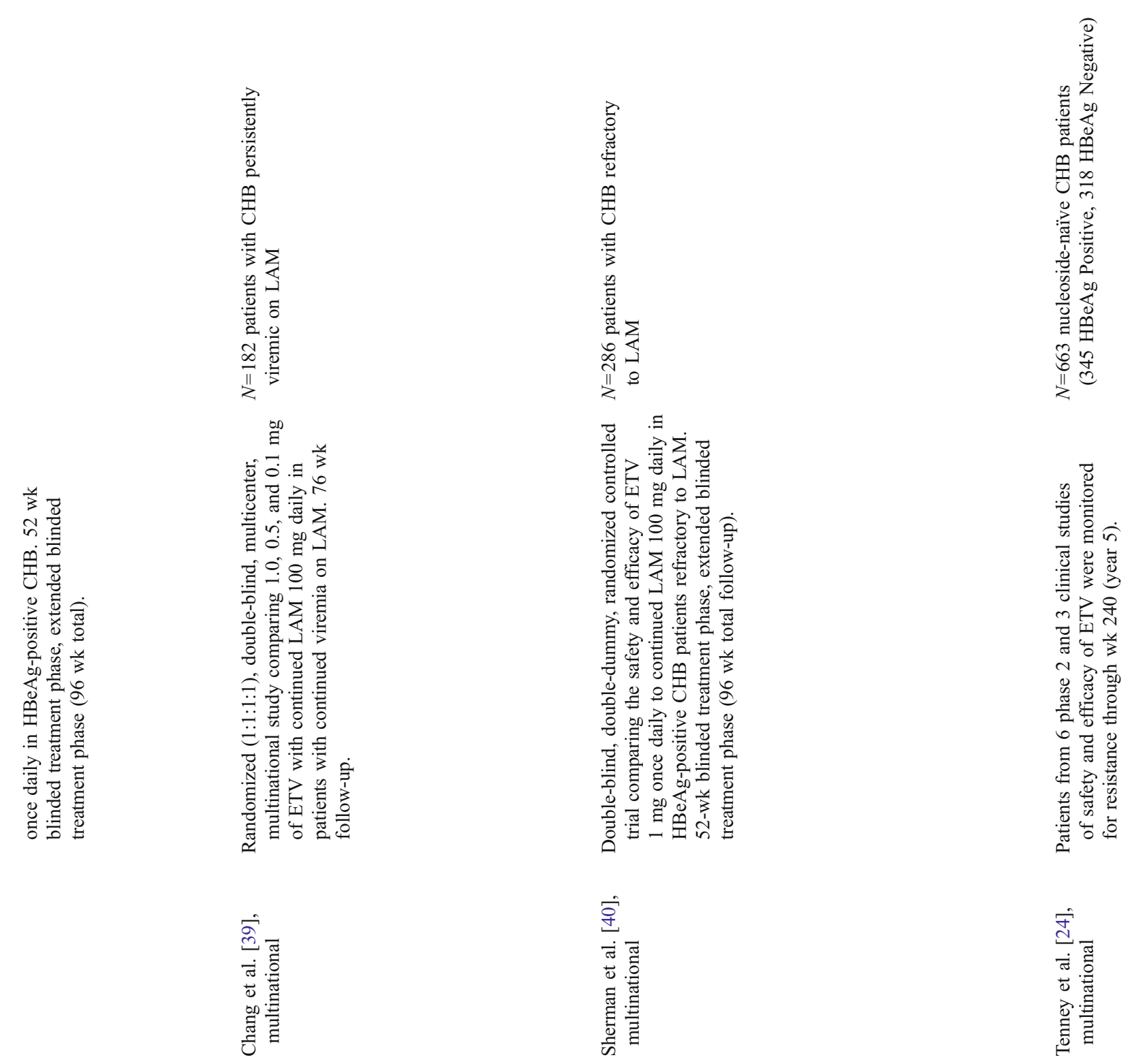




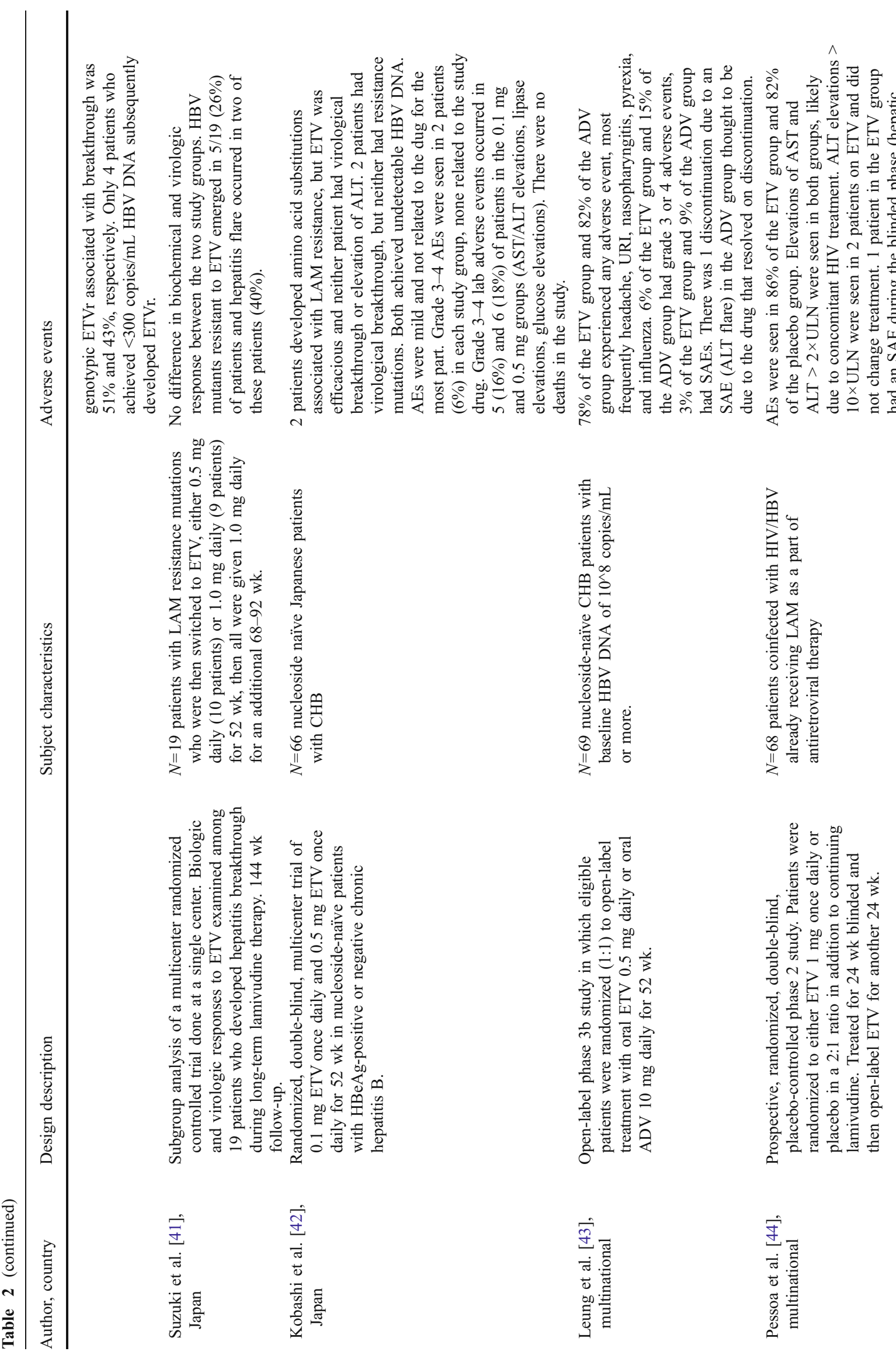




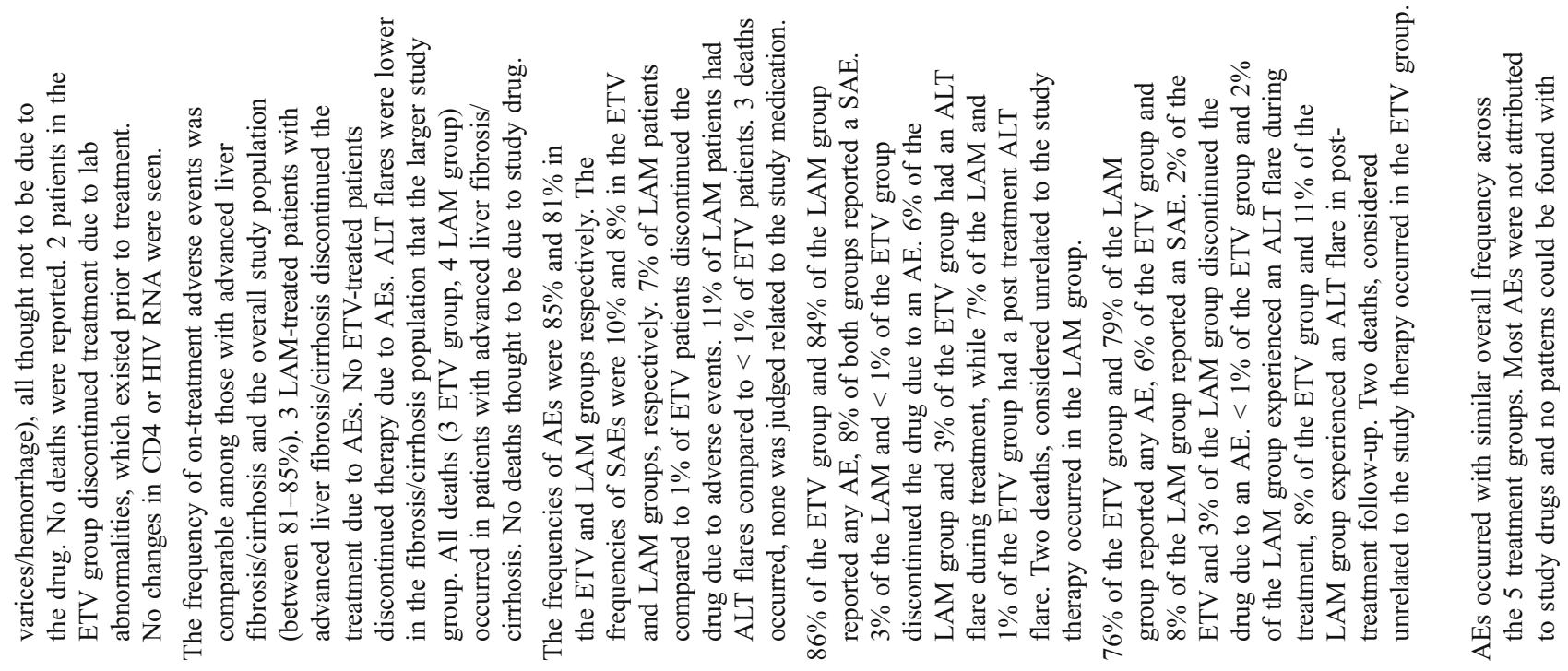
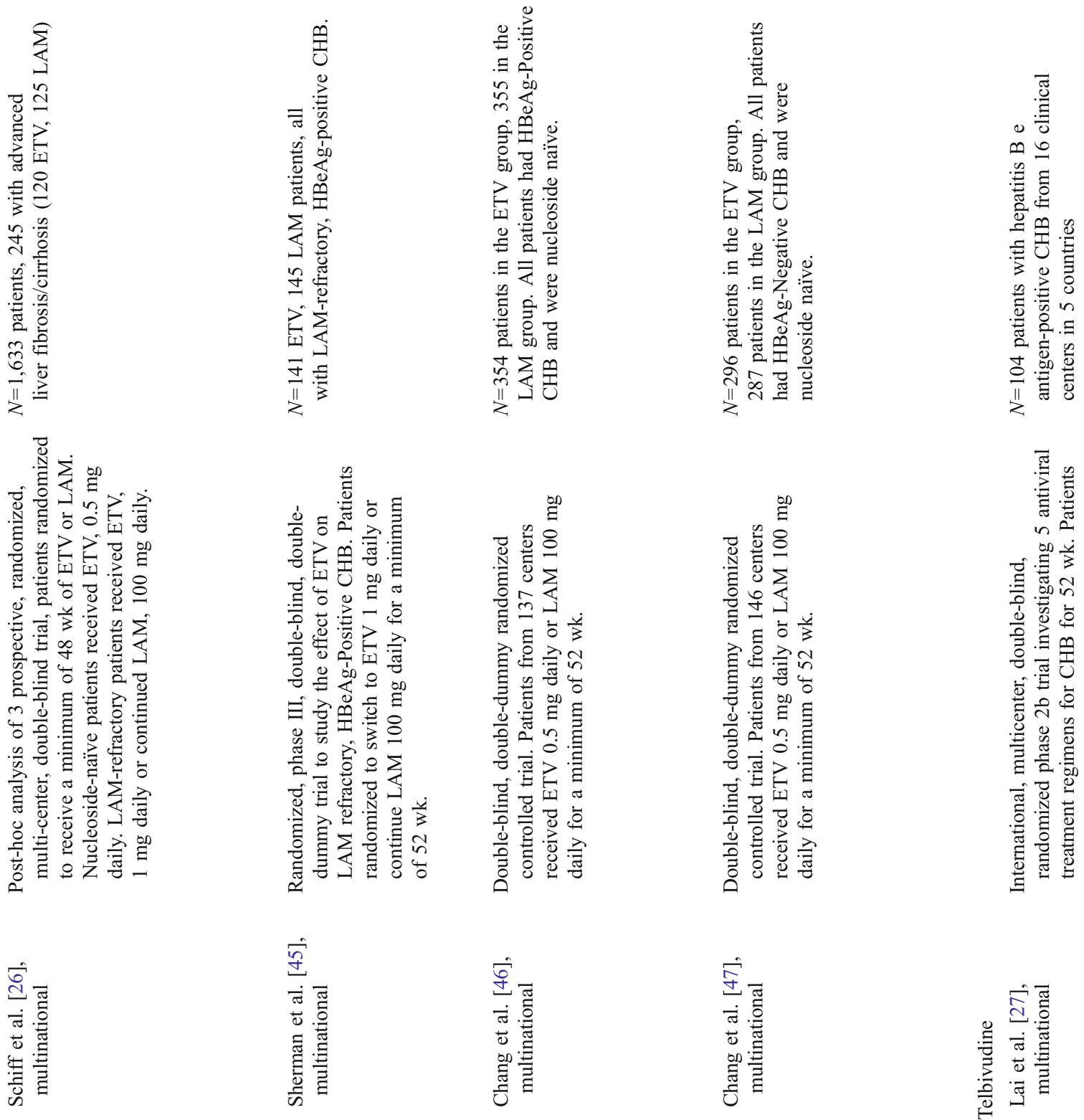


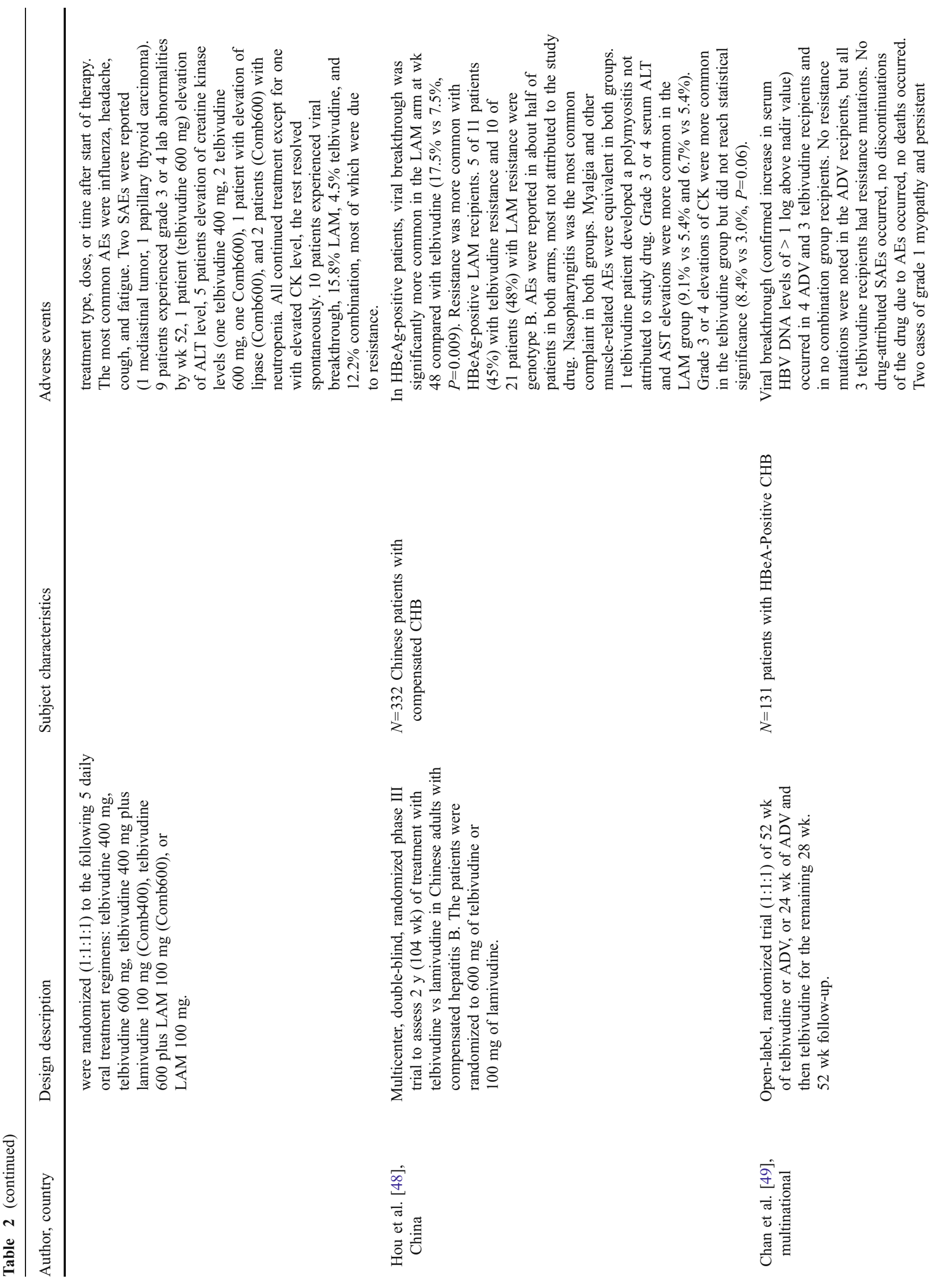




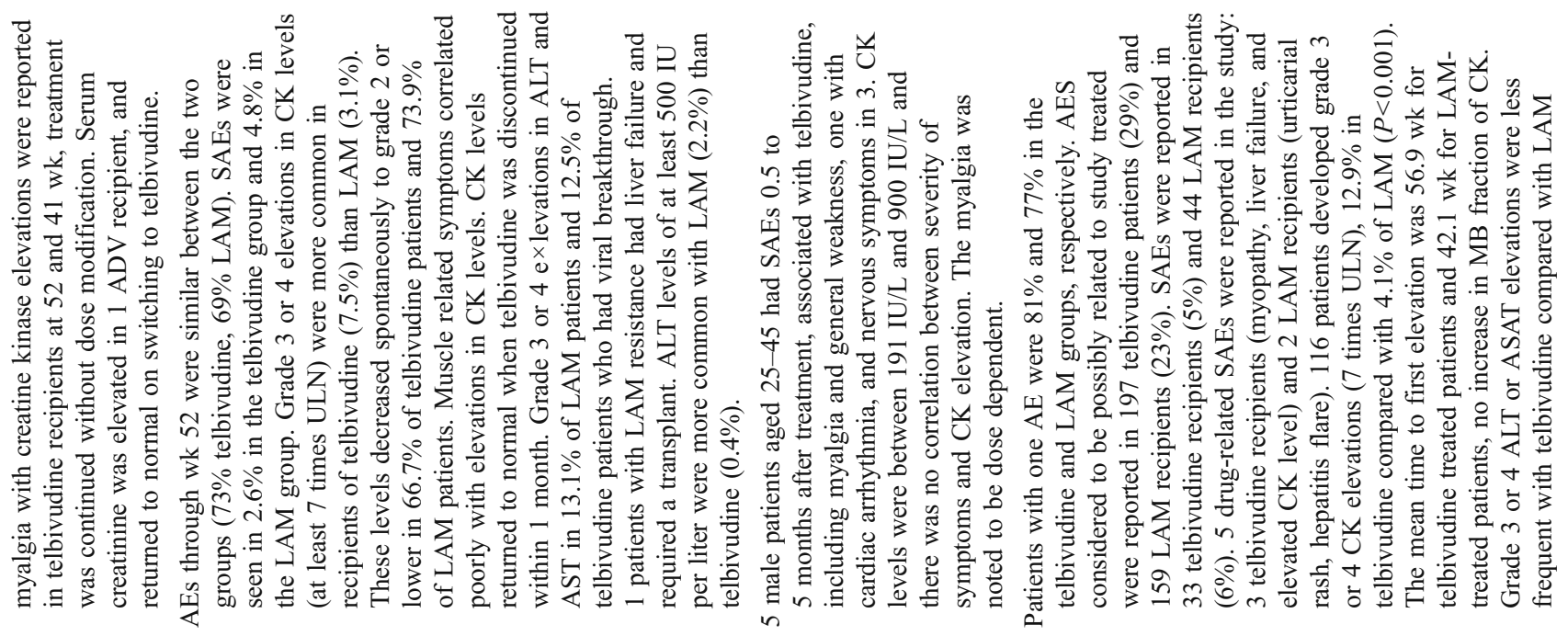

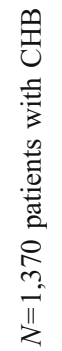
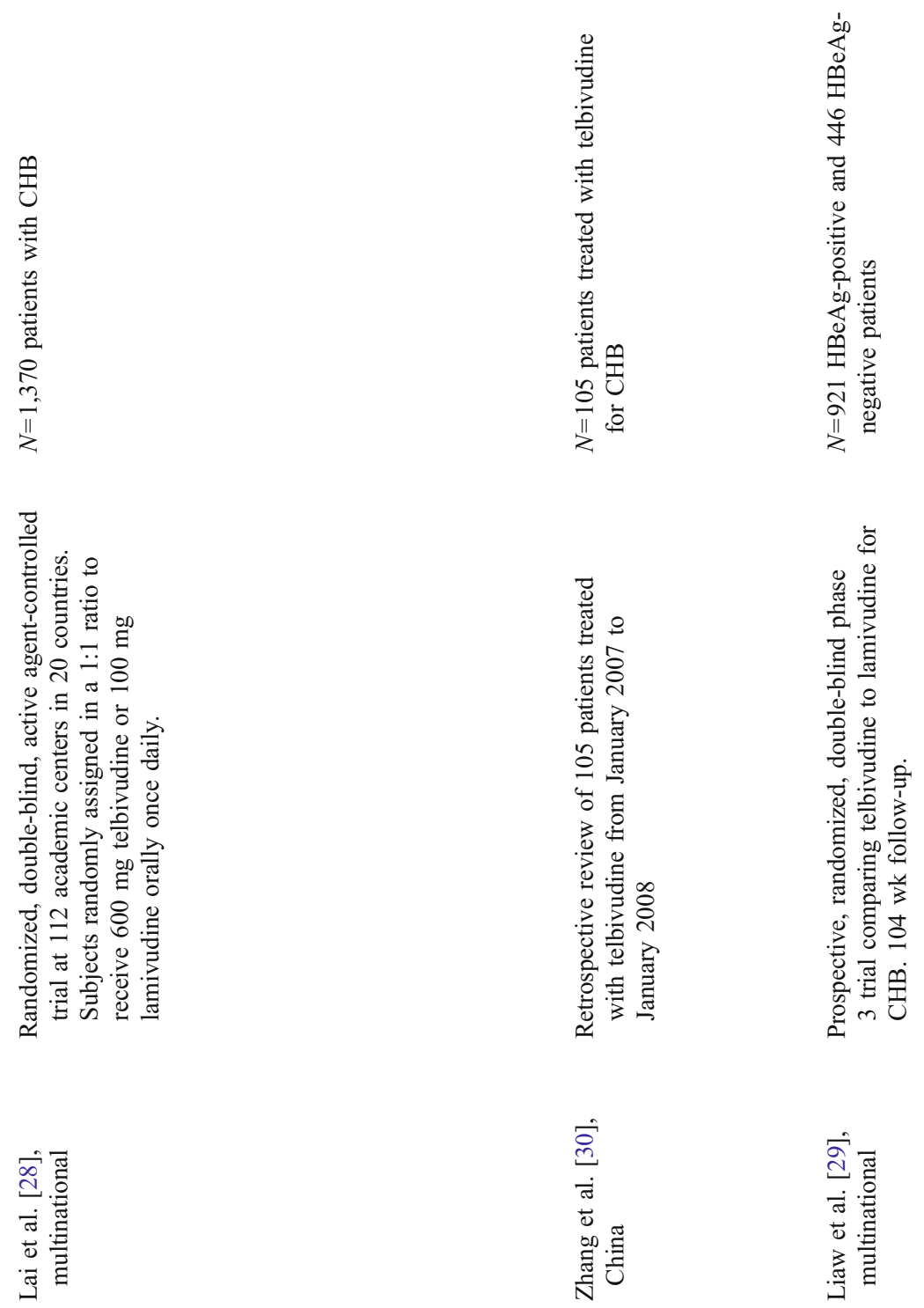


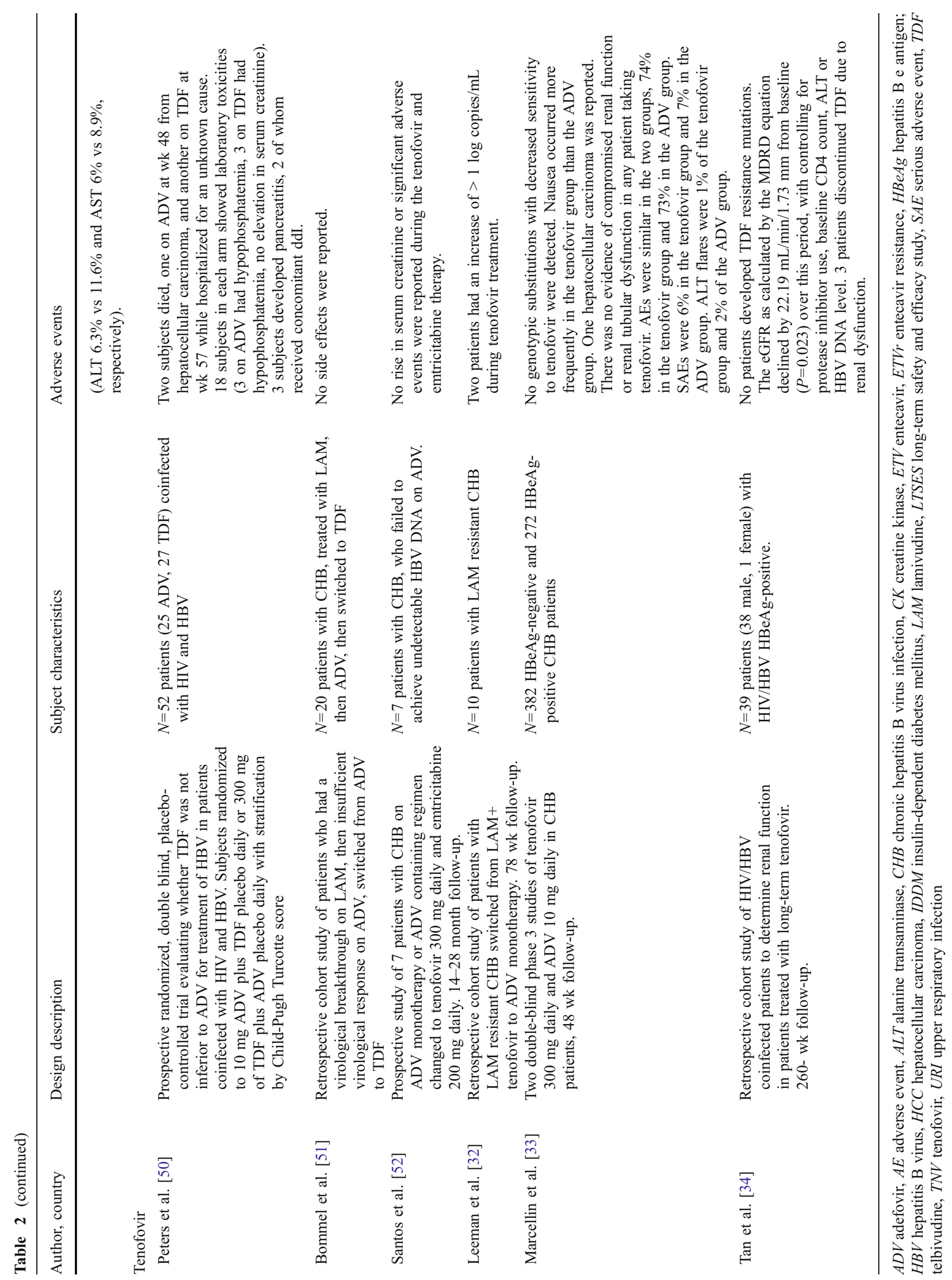


ADV for 5 years, grade 1 nephrotoxicity was seen in 3\% of patients with compensated liver disease [15]. In another study, $6 \%$ on the transplant waiting list, and $47 \%$ of those who underwent liver transplant during the study experienced grade 1 nephrotoxicity [16]. Patients in the latter two groups may have had alternate explanations for renal dysfunction such as use of other nephrotoxic medications, hepatorenal syndrome, or may have had a magnified effect of ADV due to advanced liver disease.

A retrospective matched cohort study carried out in a community setting by university investigators revealed that over 100 patient years, ADV is an independent predictor for significant deterioration of renal function, particularly with older patients, baseline renal insufficiency, and/or diabetes mellitus. In this study, incidence density for renal dysfunction was defined by treatment termination and/or development of eGFR $\leq 50 \mathrm{~mL} /$ minute, with 5 cases $/ 100$ patient years in the ADV treatment group compared to 1.36 cases $/ 100$ patient years in the unexposed group. A relative risk of the exposed to unexposed was 3.68 with $95 \%$ confidence intervals of 1.1 and 19.3. The authors stated that this may be a more realistic picture of the renal dysfunction in the community as opposed to a clinical trial [17]. Other studies have detected no change in serum creatinine at a dose of $10 \mathrm{mg}$ daily, including two double-blind, placebo-controlled trials to investigate the safety and tolerability of two dosing regimens for ADV, $10 \mathrm{mg}$ daily and $30 \mathrm{mg}$ daily. At the higher dose, patients had an increase of $0.2 \mathrm{mg} / \mathrm{dL}$ in creatinine when treated for more than 6 months [18].

The mechanism of nephrotoxicity with ADV is not elucidated; however, there is likely proximal tubular injury and a Fanconi-like renal tubular acidosis or alterations in multidrug resistance protein 4 expression in renal tubular epithelium. Dose reductions or increased dosing intervals in those with renal insufficiency and monitoring of renal function every 3 months for those with comorbidities that predispose to renal insufficiency or in patients on the drug for more than 1 year are recommended. Clinically, nephrotoxicity will manifest as slight increases in serum creatinine and decreases in serum phosphate levels occurring 4 to 12 months after starting ADV.

Resistance is a major concern emerging with use of ADV. ADV resistance may be more frequent in patients who already have LAM resistance. In an open-label trial to study mutations in LAM resistant patients, $18 \%$ of the LAM-resistant patients developed ADV resistant mutations, while none of the treatment naïve patients developed mutations to ADV [19]. In a long term safety and efficacy study following patients for 5 years on treatment, ALT flares were seen in 15 of 65 patients. These patients had ADV mutations [20]. Rare serious adverse events include nasopharyngeal cancer, spontaneous abortion, fracture, and bronchial pneumonia [21]; however, it is not certain that these are attributable to
ADV. Further long term follow-up in patients to determine adverse events associated with adefovir is needed.

\section{Entecavir}

Entecavir (ETV) is a nucleoside analogue of 2'deoxyguanosine and inhibits HBV replication at three different steps: priming of HBV DNA polymerase, reverse transcription of the negative-strand HBV DNA, and synthesis of the positive-strand HBV DNA [2]. It was approved in 2005 at a dose of $0.5 \mathrm{mg} / \mathrm{d}$ for treatment-naïve CHB patients and $1.0 \mathrm{mg} / \mathrm{d}$ for LAM-resistant patients. In animal studies, there has been a higher incidence of solid tumors; long-term human studies are underway.

Resistance is rare with entecavir in nucleoside treatment naïve patients and when it does occur, it tends to happen in those patients who already have LAM resistance. In a double-blind, placebo-controlled study comparing the efficacy of entecavir, $0.5 \mathrm{mg}$ once daily, and lamivudine, $100 \mathrm{mg}$ once daily, in $\mathrm{HBeAg}$-positive $\mathrm{CHB}$, there was no virologic breakthrough due to entecavir resistance at 96 weeks. In lamivudine refractory patients, genotypic resistance to entecavir was $51 \%[22,23]$. In 5 years of follow-up of nucleoside-naïve patients from six phase 2 and 3 clinical studies of safety and efficacy of ETV, the cumulative probability of genotypic entecavir resistance (ETVr) and genotypic ETVr associated with virologic breakthrough was $1.2 \%$ and $0.8 \%$, respectively. In LAMrefractory patients, the 5-year cumulative probability of genotypic ETVr and genotypic ETVr associated with breakthrough was $51 \%$ and $43 \%$, respectively. Only four patients who achieved less than 300 copies/mL HBV DNA subsequently developed ETVr [24]. The 6-year resistance data for entecavir reveal a cumulative probability of genotypic resistance of $1.2 \%$ in nucleoside-naïve patients and $57 \%$ in LAM-resistant patients. A total of 74 of 187 LAM-refractory patients (40\%) achieved HBV DNA less than $300 \mathrm{c} / \mathrm{mL}$ while on treatment with entecavir and of those 74 patients, only $5(7 \%)$ developed genotypic resistance. The 6-year resistance data support the conclusion that ETV has a high genetic barrier to resistance in nucleosidenaïve patients. Even in the lamivudine-refractory patients, favorable prognostic subgroups can be identified by response to treatment with entecavir [25].

ETV is generally well tolerated even in patients with advanced fibrosis and cirrhosis. In a post-hoc analysis of three prospective, randomized, multicenter, double-blind trials, patients with $\mathrm{CHB}$ and advanced hepatic fibrosis or cirrhosis were randomly assigned to receive a minimum of 48 weeks of ETV or LAM. Nucleoside-naïve patients received ETV, $0.5 \mathrm{mg}$ daily. LAM-refractory patients received entecavir, $1 \mathrm{mg}$ daily, or continued LAM at $100 \mathrm{mg}$ daily. The frequency of on-treatment adverse events was comparable 
among those with advanced liver fibrosis/cirrhosis and the overall study population. No entecavir-treated patients discontinued therapy due to adverse events [26]. Entecavir has been proven effective against $\mathrm{CHB}$, but continued surveillance is necessary to determine its long-term safety.

\section{Telbivudine}

Telbivudine is a potent L-nucleoside analogue approved for the treatment of CHB in 2006 at a dose of $600 \mathrm{mg} / \mathrm{d}$. It is more potent than lamivudine in suppressing HBV replication, but it is associated with a high rate of viral resistance, reflecting mutations cross-resistant with lamivudine, so monotherapy is limited $[2 \bullet \cdot]$. The safety profile of telbivudine looked similar to that of lamivudine in registration trials, but at 2 years, significant adverse effects were noted [27, 28]. Creatine phosphokinase (CPK) elevations greater than 7 times the upper limit of normal were noted more frequently in patients on telbivudine at 2 years as compared to patients on lamivudine ( $12.9 \%$ with telbivudine compared to $4.1 \%$ with lamivudine treated patients, $P<0.001$ ) [29]. Although CPK levels were elevated to be between $191 \mathrm{IU} / \mathrm{L}$ and $900 \mathrm{IU} / \mathrm{L}$, there was no correlation with severity of muscle symptoms and absolute CPK elevations. On the other hand, subjective myalgia was noted to be dose dependent [30]. Two patients developed myopathy that resolved with drug discontinuation. Given these reports, it is recommended that patients taking telbivudine undergo monitoring for musculoskeletal symptoms and CPK levels before commencing therapy and then every 3 months during therapy.

Reports exist of moderately severe peripheral neuropathy in $17 \%$ of patients treated with telbivudine and peginterferon alfa-2a [31]. Accordingly, telbivudine is not recommended for use in combination with peginterferon at this time. Telbivudine in combination with adefovir and tenofovir is currently being studied.

\section{Tenofovir}

Tenofovir disoproxil fumarate is a nucleotide analogue that was approved for HIV infection as Viread (tenofovir alone) or Truvada (tenofovir plus emtricitabine as a single pill) (both, Gilead Sciences, Foster City, CA). It was approved for CHB at a dose of $300 \mathrm{mg} / \mathrm{d}$ in 2008. It is structurally similar to adefovir, but is less nephrotoxic, so higher doses can be used, conferring better antiviral activity in clinical studies $[2 \bullet \bullet, 32,33]$. Tenofovir is currently recommended as part of the nucleos[t]ide reverse transcriptase inhibitor (NRTI) backbone in combination with a non-nucleoside reverse transcriptase inhibitor (NNRTI) or protease inhibitor as first line highly active antiretroviral therapy, which makes it an excellent choice for therapy in coinfected individuals [34]. To date, neither phenotypic nor genotypic resistance to CHB has been identified with tenofovir. It is effective against lamivudine-resistant strains of CHB.

A $4 \%$ rate of nephrotoxicity is reported in HIV patients taking tenofovir, but most were able to continue tenofovir at reduced doses. Accordingly, it is recommended that serum creatinine, phosphate levels, and urinalysis be monitored every 3 months in patients taking tenofovir, because the nephrotoxicity from this drug is thought to be reversible with dose reduction or discontinuation. Decreased bone density and osteomalacia have also been described in HIV patients taking tenofovir. Bone density measurements and calcium and vitamin D supplementation are recommended in patients taking tenofovir for HIV. The experience with tenofovir in CHB is still in its early stages, and long-term data regarding nephrotoxicity, decreased bone density, and osteomalacia in patients with CHB has not been determined.

\section{Conclusions}

The five approved nucleoside/nucleotide drugs for CHB carry much promise for the treatment of this disease. The side effects associated with these medications are clinically significant, and close monitoring of patients while on therapy is indicated. Future studies to address the longterm safety profile of these nucleoside/nucleotide analogues given for CHB are needed or currently underway. These include studies assessing nephrotoxicity, myopathy, mitochondrial toxicity, bone mineral density, and drug resistance. Additionally, further studies are needed to assess the safety of nucleoside/nucleotide analogues in special patient populations including pregnant women, children, the elderly, and patients with decompensated liver disease.

Disclosure Dr. Han has received grant support from Bristol-Myers Squibb and Gilead, and has served on speakers' bureaus and as a consultant for Bristol-Myers Squibb, Gilead, and Idenix/Novartis. No other potential conflict of interest relevant to this article was reported.

Open Access This article is distributed under the terms of the Creative Commons Attribution Noncommercial License which permits any noncommercial use, distribution, and reproduction in any medium, provided the original author(s) and source are credited.

\section{References}

Papers of particular interest, published recently, have been highlighted as:

•- Of major importance

1. Kao JH, Chen DS: The natural history of hepatitis B virus infection. In Hepatitis B Virus. Edited by Lai CL, Locarnini S. London: International Medical Press; 2002:161-172. 
2. •- Lok ASF, McMahon BJ: Chronic hepatitis B: update 2009. Hepatology 2009, 50 (3): 1-36. This article presents the most upto-date American guidelines for the treatment of chronic hepatitis $B$; these are the national standard of care.

3. •• European Association for the Study of the Liver: EASL Clinical Practice Guidelines: management of chronic hepatitis B. J Hepatol 2009, 50:227-242. This article presents the most up-to-date European guidelines for the treatment of chronic hepatitis B, which help to put the American Association for the Study of Liver Diseases guidelines into perspective.

4. •• Fontana RJ: Side effects of long-term oral antiviral therapy for hepatitis B. Hepatology 2009; 49: S185-S195. This article presents the most complete narrative review on the side effects of oral antiviral therapy for hepatitis $B$.

5. Birkus G, Hitchcock MJ, Cihlar T: Assessment of mitochondrial toxicity in human cells treated with tenofovir: comparison with other nucleoside reverse transcriptase inhibitors. Antimicrob Agents Chemo 2002;46:716-723.

6. McKenzie R, Fried MW, Sallie R, et al.: Hepatic failure and lactic acidosis due to fialuridine (FIAU), an investigational nucleoside analog for chronic hepatitis B. N Engl J Med 1995, 333:10991105.

7. Lange CM, Bojunga J, Hofmann WP, et al.: Severe lactic acidosis during treatment of chronic hepatitis $\mathrm{B}$ with entecavir in patients with impaired liver function. Hepatology 2009, 50:2001-2006.

8. Lamivudine [package insert]. Research Triangle Park, NC: Glaxo SmithKline; 2008.

9. Adefovir [package insert]. Foster City, CA: Gilead Sciences, Inc.; 2008.

10. Entecavir [package insert]. Princeton, NJ: Bristol-Meyers Squibb; 2009.

11. Telbivudine [package insert]. Cambridge, MA: Idenix Pharmaceuticals; 2008.

12. Tenofovir [package insert]. Foster City, CA: Gilead Sciences, Inc.; 2008.

13. Lai CL, Chien RN, Leung NW, et al.: A one-year trial of lamivudine for chronic hepatitis B. N Engl J Med 1998, 339:61-68.

14. Benhamou Y, Thibault V, Vig P, et al.: Safety and efficacy of adefovir dipivoxil in patients infected with lamivudine-resistant hepatitis B and HIV-1. J Hepatol 2006, 44:62-67.

15. Hadziyannis SJ, Tassopoulos NC, Heathcote EJ, et al.: Long-term therapy with adefovir dipivoxil for $\mathrm{HBeAg}$-negative chronic hepatitis B for up to 5 years. Gastroenterology 2006, 131:17431751.

16. Schiff E, Ching-Lung L, Hadziyannis S, et al.: Adefovir dipivoxil for wait-listed and post-liver transplantation patients with lamivudine-resistant hepatitis B: final long-term results. Liver Transpl 2007, 13:349-360.

17. Ha NB, Ha NB, Garcia RT, et al.: Renal dysfunction in chronic hepatitis B patients treated with adefovir dipivoxil. Hepatology 2009, 50: 727-734

18. Izzedine H, Hulot JS, Launay-Vacher V, et al.: Renal Safety of adefovir dipivoxil in patients with chronic hepatitis B: two double-blind, randomized, placebo-controlled studies. Kidney Int 2004, 66: 1153-1158.

19. Lee YS, Dong JS, Young-Suk L, et al.: Increased risk of adefovir resistance in patients with lamivudine-resistant chronic hepatitis B after 48 weeks of adefovir dipivoxil monotherapy. Hepatology 2006, 43: 1385-1391.

20. Marcellin P, Chang TT, Lim SGL, et al.: Long-term efficacy and safety of adefovir dipivoxil for the treatment of hepatitis B e antigen-positive chronic hepatitis B. Hepatology 2008, 48:750 758.

21. Zeng M, Mao Y, Yao G, et al.: A double-blind randomized trial of adefovir dipivoxil in chinese subjects with $\mathrm{HBeAg}$-positive chronic hepatitis B. Hepatology 2006, 44: 108-116.
22. Gish RG, Lok AS, Chang TT, et al.: Entecavir therapy for up to 96 weeks in patients with HBeAg-positive chronic hepatitis B. Gastroenterology 2007, 133: 1437-1444.

23. Han SB, Chang TT, Chao YC, et al.: Five years of continuous entecavir for nucleoside-naïve $\mathrm{HBeAg}^{+}$chronic hepatitis B: results from study ETV-901. Hepatology 2008, 48: 705A.

24. Tenney DJ, Rose RE, Baldick CJ, et al.: Long-term monitoring shows hepatitis B virus resistance to entecavir in nucleoside-naïve patients is rare through 5 years of therapy. Hepatology 2009, 49: $1503-1514$

25. Tenney DJ, Pokorowski KA, Rose RE, et al.: Entecavir maintains a high genetic barrier to HBV resistance through 6 years in naïve patients. Presented at Digestive Disease Week. Chicago, IL; May 30-June 4, 2009

26. Schiff E, Simsek H, Lee WM, et al.: Efficacy and safety of entecavir in patients with chronic hepatitis B and advanced hepatic fibrosis or cirrhosis. Am J Gastroenterol 2008, 103: $2776-2783$

27. Lai CL, Leung N, Teo EK, et al.: A 1-year trial of telbivudine, lamivudine, and the combination in patients with hepatitis B e antigenpositive chronic hepatitis B. Gastroenterology 2005, 129: 528-536.

28. Lai CL, Gane E, Liaw YF, et al.: Telbivudine versus lamivudine in patients with chronic hepatitis B. N Engl J Med 2007, 357:25762588.

29. Liaw YF, Gane E, Leung N, et al.: 2-Year GLOBE trial results: telbivudine is superior to lamivudine in patients with chronic hepatitis B. Gastroenterology 2009, 136:486-495.

30. Zhang XS, Jin R, Zhang SB, et al.: Clinical features of adverse reactions associated with telbivudine. World J Gastroenterol 2008 , 14: 3549-3553.

31. US Food and Drug Administration: Potential signals of serious risks/ new safety information identified from the adverse event reporting system (AERS) between January-March 2008. Available at http:// www.fda.gov/Drugs/GuidanceComplianceRegulatoryInformation/ Surveillance/AdverseDrugEffects/ucm082196.htm. Accessed November 2009.

32. Leemans WF, Janssen HLA, Niesters HGM, et al.: Switching patients with lamivudine resistant chronic hepatitis $\mathrm{B}$ virus from tenofovir to adefovir results in less potent HBV-DNA suppression. J Viral Hepat 2008, 15:108-114.

33. Marcellin P, Heathcoate EJ, Buti M, et al.: Tenofovir disoproxil fumarate versus adefovir dipivoxil for chronic hepatitis B. N Engl J Med 2008, 359:2442-2455.

34. Tan LKK, Gilleece Y, Mandalia S: Reduced glomerular filtration rate but sustained virologic response in HIV/hepatitis B coinfected individuals on long-term tenofovir. Journal of Viral Hepatitis 2009, 16: 471-478.

35. Sung JJY, Lai JK, Zeuzem S, et al.: Lamivudine compared with lamivudine and adefovir dipivoxil for the treatment of $\mathrm{HBeAg}$ positive chronic hepatitis B. J Hepatol 2008: 728-735.

36. Hannon H, Bagnis CI, Benhamou Y, et al.: The renal tolerance of low-dose adefovir dipivoxil by lamivudine-resistant individuals co-infected with hepatitis B and HIV. Nephrol Dial Transplant, 19: 386-390.

37. Pellicelli AM, Barbaro G, Francavilla R, et al.: Adefovir and lamivudine in combination compared with adefovir monotherapy in $\mathrm{HBeAg-negative} \mathrm{adults} \mathrm{with} \mathrm{chronic} \mathrm{hepatitis} \mathrm{B} \mathrm{virus} \mathrm{infection} \mathrm{and}$ clinical or virologic resistance to lamivudine: a retrospective, multicenter, nonrandomized, open-label study. Clin Ther 2008, 30:317-323

38. Jonas MM, Kelly D, Pollack K, et al.: Safety, efficacy, and pharmacokinetics of adefovir dipivoxil in children and adolescents (age 2 to $<18$ years) with chronic hepatitis B. Hepatology 2008, 47: $1863-1871$

39. Chang TT, Gish RG, Hadziyannis SJ, et al.: A dose-ranging study of the efficacy and tolerability of entecavir in lamivudine- 
refractory chronic hepatitis B patients. Gastroenterology 2005, 129: 1198-1209.

40. Sherman M, Yurdaydin C, Simsek H, et al.: Entecavir therapy for lamivudine-refractory chronic hepatitis B: improved virologic, biochemical, and serology outcomes through 96 weeks. Hepatology 2008, 48: 99-108.

41. Suzuki F, Toyoda J, Katano Y, et al.: Efficacy and safety of entecavir in lamivudine-refractory patients with chronic hepatitis B: randomized controlled trial in Japanese patients. J Gastroenterol Hepatol 2008, 23: 1320-1326.

42. Kobashi H, Takaguchi K, Ikeda H, et al.: Efficacy and safety of entecavir in nucleoside-naïve, chronic hepatitis b patients: phase II clinical study in Japan. J Gastroenterol Hepatol 2009, 24: 255261.

43. Leung N, Peng CY, Hann HW, et al.: Early hepatitis B virus DNA reduction in hepatitis $\mathrm{B}$ e antigen-positive patients with chronic hepatitis B: a randomized international study of entecavir versus adefovir. Hepatology 2009, 49: 72-79.

44. Pessoa MG, Gazzard B, Huang AK, et al.: Efficacy and safety of entecavir for chronic HBV in HIV/HBV coinfected patients receiving lamivudine as part of antiretroviral therapy. AIDS 2008, 22: 1779-1787.

45. Sherman M, Yurdaydin C, Sollano J, et al.: Entecavir for treatment of lamivudine-refractory, $\mathrm{HBeAg}$-positive chronic hepatitis B. Gastroenterology 2006, 130:2039-2049.
46. Chang TT, Gish RG, Hadziyannis SJ, et al.: A dose-ranging study of the efficacy and tolerability of entecavir in lamivudinerefractory chronic hepatitis B patients. Gastroenterology 2005, 129:1198-1209.

47. Chang TT, Gish RG, de Man R, et al.: A comparison of entecavir and lamivudine for $\mathrm{HBeAg}$-positive chronic hepatitis B. N Engl J Med 2006, 354:1001-1010.

48. Hou J, Yin YK, $\mathrm{Xu} \mathrm{D}$, et al.: Telbivudine versus lamivudine in Chinese patients with chronic hepatitis B: results at 1 year of a randomized, double-blind trial. Hepatology 2008, 47: 447454.

49. Chan HLY, Heathcote J, Marcellin P, et al.: Treatment of hepatitis $\mathrm{B}$ e antigen-positive chronic hepatitis with telbivudine or adefovir. Ann Intern Med. 2007, 147: 745-754.

50. Peters MG, Andersen J, Lynch P, et al.: Randomized controlled study of tenofovir and adefovir in chronic hepatitis B virus and HIV infection: ACTG A5127. Hepatology 2006, 44: 1110-1116.

51. Bommel FV, Zollner B, Sarrazin C, et al.: Tenofovir for patients with lamivudine-resistant hepatitis B virus (HBV) infection and high HBV DNA level during adefovir therapy. Hepatology 2006, 44:318325.

52. Santos SA, Uriel AJ, Park JS, et al.: Effect of switching to tenofovir with emtricitabine in patients with chronic hepatitis B failing to respond to an adefovir-containing regimen. Eur J Gastroenterol Hepatol 2006, 18:1247-1253. 